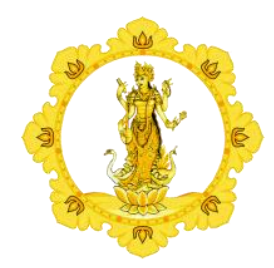

KALANGWAN

JURNAL PENDIDIKAN AGAMA, BAHASA DAN SASTRA

Vol. 11 No. 1 Maret 2021

\begin{tabular}{|l|l|l|}
\hline p-ISSN : 1979-634X & e-ISSN : 2686-0252 & http://ejournal.ihdn.ac.id/index.php/Kalangwan \\
\hline
\end{tabular}

\title{
AJARAN BHATARA KUMARA DALAM TUTUR KUMARA TATWA DAN PENGARUH TERHADAP KEHIDUPAN MANUSIA
}

\author{
Oleh : \\ I Wayan Artayasa \\ Universitas Hindu Negeri I Gusti Bagus Sugriwa Denpasar \\ E-mail: yanarta84@gmail.com
}

Diterima 13 Januari 2021, direvisi 15 Januari 2021, diterbitkan 31 Maret 2021

\begin{abstract}
Hindus considered Bhatara Kumara in Bali as a protector or guardian deity for newborn children. Offering and worshiping Bhatara Kumara is very important to do every day to protect or give children gifts. However, in Tutur Kumara Tatwa, Bhatara Kumara teachings are not only for children but for all people.

The teachings conveyed are a form of self-control in this life. The teaching or education in Tutur Kumara Tatwa certainly has implications for human life, especially in Bali. Children's education is essential to do from an early age to develop good character. Good character is not only for children but also applies to all human beings. According to Tutur Kumara Tatwa, character education from Bhatara Siwa to Bhatara Kumara originated from a field where Bhatara Kumara was grazing called Argakuruksana. Bhatara Kumara felt like life in solitude. During his life as a shepherd, he had experienced many ups and downs. It is what can be learned as teaching or values in life that can affect human life.

Bhatara Kumara was blessed or awarded by Bhatara Shiva to stay young, achieving eternal happiness. Bhatara Kumara is represented as the god of a baby. It means that babies should have received character education from their parents. Bhatara Kumara's role in human life, especially for Bali's Hindu community, is seen as the God of children from birth to Telung Oton's age (630 days). Bhatara Kumara is placed in Pelangkiran and is believed to be the child's protector or guardian.
\end{abstract}

Keywords: Teachings of Bhatara Kumara, Tutur, Human Life. 


\section{PENDAHULUAN}

Bhatara Kumara bagi umat Hindu di Bali merupakan Dewa pelindung atau penjaga khusunya anak-anak terutama anak baru lahir sampai umur delapan belas bulan atau telung oton. Bhatara Kumara oleh umat Hindu di Bali dianggap sebagai ista dewata bagi anakanak, oleh karena itu sangat penting dilakukan pemujaan setiap hari untuk memberikan perlindungan atau memberikan anugerah kepada bayi. Menurut tutur kumara tatwa, Bhatara atau Dewa Kumara tidak hanya untuk anak-anak saja, tetapi bagi semua kalangan umur manusia, terutama dapat memberikan ajaran dan pendidikan yang bersifat religius. Pendidikan sangat penting diberikan kepada anak, lebih-lebih selama anak masih dalam kandungan, setelah lahir, tumbuh remaja, dewasa maupun sudah tua.

Ajaran atau pendidikan yang terkandung dalam tutur kumara tatwa tentunya dapat berimplikasi terhadap kehidupan manusia terutama di Bali. Pendidikan anak sangat penting dilakukan sejak dini agar nantinya bisa tumbuh berkembang berkarakter yang baik. Karakter yang baik bukan hanya kepada anak-anak saja tetapi berlaku kepada semua manusia. Menurut tutur kumara tatwa pendidikan karakter dari Bhatara Siwa kepada Bhatara Kumara berawal dari sebuah ladang tempat penggembalaan Bhatara Kumara, yang disebut Argakuruksana. Bhatara Kumara merasa hidup dalam kesendirian. Selama hidup sebagai pegembala sudah banyak suka duka dan penderitaan yang dialami. Hal inilah yang dapat dipetik sebagai sebuah ajaran atau niali-nilai dalam kehidupan yang dapat mempengaruhi kehidupan manusia.

Bhatara Kumara diberkati atau dianugrahi oleh Bhatara Siwa supaya tetap muda yang tentunya dalam hal ini berhasil mencapai kebahagian kekal abadi. Bhatara Kumara disimbulkan sebagai dewanya bayi, itu artinya dari bayi mestinya sudah mendapatkan pendidikan karakter dari orang tuannya. Pentingnya mendidik anak dari usia dini, karena sekarang era globalisasi serba gadget, teknologi semakin berkembang tidak bisa luput dari perkembangan zaman sekarang ini. Perkembangan zaman globalisasi kehidupan semakin kompleks. Akibat negatif dari perkembangan zaman banyak siswa, anak-anak yang nakal, tidak sopan, tidak beretika dan lebih parah lagi adanya degradasi moral. Melalui tutur kumara tatwa yang merepleksikan antara orang tua dan anak (Bhatara Siwa sebagai orang tua dan Bhatara Kumara sebagai anak) sangat relepan untuk diteladani agar anak menjadi sukses dikemudian hari. Kesuksesan anak tidak bisa lepas peran orang tua dirumah, karena anak lebih banyak bersama orang tua dibandingkan dengan guru-guru di sekolah. Peran Bhatara Kumara dalam mengembangkan kehidupan manusia yang lebih baik adalah suatu sistem penanaman nilai karakter kepada manusia. Penamanam karakter meliputi komponen pengetahuan, kesadaran atau kemauan pada manusia dan tindakan untuk melaksanakan nilai-nilai tersebut. Dalam urusan kehidupan manusia yang lebih baik atau karakter semua komponen harus saling terkait.

Anak-anak lebih suka membaca berita-berita modern karena jarang mendapatkan pitutur, piteket atau cerita-cerita yang ada di Bali. Masyarakat atau anak-anak menganggap cerita-cerita yang ada dalam naskah lonta-lontar dianggap tradisional atau kuno. Sikap seperti ini harus segera ditangani oleh berbagai pihak atau komponen masyarakat yang memiliki kepedulian terhadap pelestarian dan pengembangaan sastra dan budaya Bali. Ajaran yang tertuang dalam cerita-cerita khususnya tutur mengandung nilai-nilai moral yang tinggi, sikap etika yang baik, sopan-santun dan berkarakter sesuai dengan kearifan lokal Bali. Tutur kumara tatwa, sebagai salah satu teks yang berisiskan tentang ajaran-ajaran atau nasihat-nasihat kehidupan. Sangat penting untuk dikaji lebih lanjut, sehingga dapat memberikan kontribusi atau manfaat bagi kehidupan manusia di jaman globalisasi sekarang ini.

\section{PEMBAHASAN \\ Bentuk Ajaran Bhatara Kumara dan Pengaruh Terhadap Kehidupan Manusia}


1. Kesadaran mengendalikan sifatsifat buruk dalam diri manusia

Ajaran Bhatara Kumara dalam Tutur Kumara Tatwa, diceritakan ladang tempat penggembalaan Sang Kumara yang disebut Argakuruksana. Tempat pengembalaan Argakuruksana adalah tempat menggembalakan ternak, ternak yang dimaksudkan dalam cerita tersebut adalah menernakan sifat-sifat egonya. Bhatara Kumara dalam kesendiriannya disimbulkan sebagai bentuk pengendalian diri melalui tapa atau brata. Kemudian sampai pada akhirnya muncul Bhatara Guru (Bhatara Siwa) untuk memberikan rahasia ilmu pengetahuan tentang sang diri. Hal tersebut dapat dilihat pada kutipan berikut:

Hana têgal pangonan Sang Kumara ring Argakuruksûana. Tan hana rowangira sang Kumara. Nda hetu ning tan dumarana, anghel kapwa ring pangwan. Mangkana ling sang Kumara ; "Anêmu lara hulun ing nguni mangke têka ning atuha, turung sah pàngon-angon, kasapuluh kwehnya, akweh mànak uruknya galak.(Teks Kumara Tatwa hal.6-7).

Terjemahan :

Adalah tempat penggembalaan Sang Kumara di Argakuruksana. Tidak ada temannya Sang Kumara sendirian. Karena itu, ia cepat bosan tinggal di ladang penggembalaan. Beginilah kata Sang Kumara; "Aku selalu menemukan penderitaan sejak dulu hingga tua, tidak pernah lepas dari penggembalaan". Sebanyak sepuluh (ternak) gembalaannya dan sudah beranak pinak serta galak.

Berdasarkan kutipan di atas, pengendalian sifat-sifat buruk dalam diri berlaku untuk semua umat manusia untuk kehidupan di dunia ini. Pengendalian diri sangat penting dilakukan untuk kedamaian hidup. Ulasan isi dari ajaran Bhatara Kumara tidak hanya untuk anak-anak saja tetapi untuk semua jenjang umur manusia, selama ini di Bali sebagian besar ajaran Bhatara Kumara diperuntukan bagi anak-anak yang baru lahir sampai 18 (delapan belas bulan kalender Bali) tetapi dilihat dari ajaran yang disampaikan dalam Tutur Kumara Tatwa lebih banyak ditujukan kepada umat manusia dari berbagai umur. Bentuk pengendalian diri dari sepuluh indria akan berpengaruh kepada manusia dan jika dapat mengendalikan sifat-sifat buruk yang ada dalam diri maka akan dapat menyebabkan kedamaian dan ketentraman dalam hidup ini.

Pengendalian diri yang mesti dilakukan oleh manusia yang dalam ajaran Bhatara Kumara adalah dapat dilihat pada kutipan berikut:

Nihan Sanghyang Sapta bwat jawa paramartha, rengen, sang sewaka dharma, irika hidepenta wastu tuhutuhu, sakweh gumlar ing bhur loka, ring dharmasastra paramacarita. Uniweh sloka tan twas sangksepanya, sang kawi majaraken sanghyang dharma sloka, wiharaning sang wiku kreta samaya, binwatjawa sanghyang wisesa lawan atma mwang moksanira.(Teks Kumara Tatwa hal.25).

Terjemahan:

Inilah ajian Sanghyang Sapta bwat Paramartha, wajib didengar oleh orang yang mengabdikan diri pada kebenaran. Dimulai dengan memusatkan bhatinmu secara sungguh-sungguh. Semua yang digelar di bumi, di dalam dharmasastra, cerita utama, terutama sloka. Pendeknya, para pujangga mengajarkan Sanghyang Darmasloka sebagai tempat perguruan sang wiku manakala tiba saatnya menekan lepasnya Sanghyang wisesa dengan atma dan moksanya. 
Berdasarkan kutipan di atas, mempelajari ajaran keagamaan dalam dharmasastra serta sloka-sloka yang utama akan mampu menuntun manusia pada ajaran dharma, atau dengan kata lain mengabdikan diri pada kebenaran. Setiap manusia diharapkan selalu menjalankan ajaran-ajaran dharma. Berpegang teguh pada ajaran dharma. Sehingga pada nantinya mampu mencapai moksa atau kelepasan.

Bentuk kelepasan yang dimaksud dalam hal ini adalah Bhatara Kumara sebagai simbul umat manusia dikatakan mencapai moksa atau kelepasan, itu berarti jika manusia berhasil melakukan pengendalian diri, melaksanakan ajaran-ajaran agama, menjauhi larangan-Nya maka dia bisa mencapai moksa, seperti cerita Bhatara Kumara dengan Bhatara Guru (Bhatara Siwa) menyatu. Hal tersebut dapat dilihat pada kutipan berikut.

Mangkin mênêng sang Kumara, tan gingsir agênya, mati kang wisayane; adi stithi, pasingdan, hnang hning, tutur amunah carma, lìna. Adi ngaran tan hana padanya, luput ing rùpa warna; stithi ngaran apagêh, luput ing añcala ika; pasingidan ngaran tan paduhan, luput ya mawàjña sarwa karya kartha; hêning ngaran tan karaktan, luput ing talta; tutur ngaran mêngêt, luput ing awesyana dahat ing jñana; amunah carma ngaran iku tan patulis, luput ing pamastu, ngaran pêjah sirêp ing bwana, korat. Mangkana pwa Sang Kumara, luput ing kajatin Bhàtara. (Teks Kumara Tatwa hal.9).

Terjemahan:

Sekarang Sang Kumara diam, tidak bergerak, semua nafsunya mati. Seperti : adi astiti, pasingidan, henang-hening, tutur amumah carma, lina.Adi artinya tidak ada bandingannya, luput dari rupa dan warna: astiti artinya kukuh, luput dari kegoncangan, pasingidan artinya tanpa pamerih, batinya luput dari hasil kerja, hening artinya tidak ternoda, luput dari kotoran, tutur artinya ingat, luput dari kelupaan, amunah carma artinya tanpa suratan, luput dari kutukan, maksudnya mati tidur. Demikianlah Sang Kumara luput dari hakikat kelahiran yang ditakdirkan Bhatara.

Berdasarkan kutipan di atas Bhatara Kumara ditakdirkan hidup dalam keabadian, tidak ternoda atau luput dari kekotoran. Sehingga di Bali Bhatara Kumara merupakan penjaga atau pelindung bayi yang baru lahir, dengan di stanakan pada plangkiran kumara maka dapat menjaga bayi. Bhatara Kumara diberkati atau dianugrahi oleh Bhatara Siwa supaya tetap muda yang tentunya dalam hal ini berhasil mencapai kebahagian kekal abadi. Bhatara Kumara disimbulkan sebagai dewanya penjaga bayi yang akan memberikan perlindungan dan memberikan kebahagiaan bagi umat manusia.

\section{Memberikan Perlindungan terhadap kehidupan manusia}

Kehidupan masyarakat Hindu di Bali meyakini bahwa Bhatara Kumara dipandang sebagai Dewanya anak-anak semenjak lahir sampai berumur Telung Oton (630 hari). Bhatara Kumara ditempatkan (distanakan) di Pelangkiran di atas tempat tidur sang anak. Hal ini dipercaya mampu memberikan perlindungan setiap saat kepada sang anak. Pelangkiran di atas tempat tidur anak tersebut setiap hari dipersembahkan banten atau dipuja oleh orang tua anak tersebut. Hal inilah yang memberikan perlindungan kepada anak-anak sehingga tetap terjaga dan terlindungi sampai tumbuh dewasa. Selain itu ajaran Bhatara Kumara dalam kehidupan ini juga mengajarkan ajaran karakter yang dapat menjadikan manusia memiliki karakter yang mulia. Makna Karakter dalam ini adalah Bhatara Kumara selalu hormat dengan Bhatara Guru (Bhatara Siwa) maupun kepada kakaknya Bhatara Kala. Seorang adik tidak boleh melawan kakak, tidak boleh melawan orang tua, selalu melaksanakan ajaran-Nya sampai Bhatara Kumara bisa 
mencapai kebebasan atau ketidak terikatan dengan urusan duniawi.

\section{KESIMPULAN}

Bentuk ajaran Bhatara Kumara menceritakan ladang tempat penggembalaan Sang Kumara yang disebut Argakuruksana. Tempat pengembalaan Argakuruksana adalah tempat menggembalakan ternak, ternak yang dimaksudkan dalam cerita tersebut adalah menernakan sifat-sifat ego dalam diri manusia. Kesendirian Bhatara Kumara disimbulkan sebagai bentuk pengendalian diri melalui tapa atau brata sampai pada akhirnya Bhatara Kumara berhasil mencapai kelepasan. Bentuk kelepasan yang dimaksud dalam hal ini adalah Bhatara Kumara sebagai simbul umat manusia dikatakan mencapai moksa atau kelepasan, itu berarti jika manusia berasil melakukan pengendalian diri, melaksanakan ajaran-ajaran agama dan menjauhi larangan-Nya.

Peran Bhatara Kumara sebagai memberi perlindungan kehidupan masyarakat Hindu di Bali, Bhatara Kumara dipandang sebagai Dewanya anak-anak semenjak lahir sampai berumur Telung Oton (630 hari). Bhatara Kumara ditempatkan (distanakan) di Pelangkiran di atas tempat tidur sang anak dan selalu diberikan banten atau persembahan dan dipuja. Hal inilah yang memberikan perlindungan kepada anak-anak sehingga tetap terjaga dan terlindungi sampai tumbuh dewasa.

\section{Daftar Pustaka}

Adi Armini. 2015. Peranan Anak Menurut Susastra Hindu (Mewujudkan Jati Diri Anak Hindu Sadhu-Madhuwa) Guna Widya Jurnal Pendidikan Hindu. Jurnal Volume 2, No 1. Fakultas Dharma Acarya IHDN Denpasar

Dinas Kebudayaan Provinsi Bali. 2003. Kajian Naskah Lontar Tutur Kumaratatwa. Denpasar

Surada, I Made. 2016. Hakikat Brahman Menurut Filsafat Ketuhanan Vedanta. Prosiding Seminar Nasional IHDN Denpasar

Wiana, I Ketut. 2002. Makna Upacara Yadnya dalam Agama Hindu. Surabaya: Paramita.

Wiana. I Ketut. 2006. Sembahyang Menurut Hindu. Surabaya : Paramita

Yendra. 2009. Kanda Empat Dewa Manusia Setengah Dewa Sakti Manderaguna. Paramita : Surabaya

Zoetmulder, P.J. S.O. Robson. 2011. Kamus Jawa Kuna- Indonesia. Cetakan keenam (Diterjemahkan Oleh Darusuprapta dan Sumarti Suprayitna). Jakarta: PT. Gramedia Pustaka Utama. 